\title{
Marine scour and offshore wind - lessons learnt and future challenges
}

\author{
John M Harris ${ }^{1}$, Richard J S Whitehouse ${ }^{1}$, James \\ Sutherland ${ }^{1}$
}

${ }^{1}$ HR Wallingford, Howbery Park, Wallingford, Oxfordshire OX10 8BA, UK (Email: j.harris@hrwallingford.co.uk)

Proceedings of the ASME 2011 30th International Conference on Ocean, Offshore and Arctic Engineering, OMAE2011, June 19-24, 2011, Rotterdam, The Netherlands

\section{Abstract}

The drive for developing marine offshore renewables has led to specific requirements for scour hazard assessment relating to the associated foundation structures and the cabling necessary for in-field transmission and power export. To date within the United Kingdom (UK) a number of demonstrator projects have been constructed covering wind, wave and tidal generation. However, only offshore wind has been developed at large-scale at present as part of two rounds of commercial development of offshore wind farms (OWFs). In June 2008, The Crown Estate, responsible for licensing seabed use, announced proposals for a third round of offshore wind farms to develop an additional $25 \mathrm{GW}$ of energy to the $8 \mathrm{GW}$ already planned for under Rounds 1 and 2. The size of these Round 3 developments will vary, but the largest of these zones will involve the construction of around 2500 seabed foundation structures.

Under Round 1 and 2 developments monopile and jacket type foundations have been used, although several other European (non UK) wind farms have been built using gravity base foundations. For a wind turbine the foundations may account for up to $35 \%$ of the installed cost. Therefore, one of the future challenges for large volume installation of offshore wind is the control and minimization of these costs.

For tidal energy devices one of the principal requirements for many of the devices proposed is their placement in areas of strong tidal energy, and this has implications not only for the stability of the foundation option, but also for the construction methodology.

Similarly wave energy devices are designed to be located in shallow, coastal environments as either floating or bottom mounted systems. These devices, by design, are intended to be located in environments with strong wave action. This may be substantial during storm events, which has implications for the integrity of the anchoring system keeping the wave device on station or the design of the device if it is seabed mounted.

This paper will explore the lessons learnt from existing offshore wind farm developments as this represents the principal body of collected monitoring data. Using these data the paper will outline some of the challenges facing the offshore renewable industry in respect of the foundation designs and specifically the requirements for scour hazard assessment using the combined experience from those developments currently operational or under construction. 


\section{Introduction}

In 2005, a Research Advisory Group (RAG) was established by the Department for Trade and Industry (DTI) to consider research priorities in relation to the potential environmental impacts of offshore wind farm developments and their impacts on other users of the sea. Three priority research projects were taken forward:

- Review of Round 1 sediment process monitoring data - lessons learnt (SED01);

- Dynamics of scour pits and scour protection (SED02); and

- Review of channel migration (SED06)

The aim of SED01 was to draw together the sediment process monitoring work carried out on Round 1 offshore wind farm developments and review the methods, data, results and impacts in order to identify lessons learnt and to provide relevant recommendations for monitoring of Round 2 developments (DECC, 2008a), whilst establishing an accessible evidence base. SED02 dealt specifically with those aspects of sediment monitoring related to scouring around wind turbine foundations (DECC, 2008b) with the aim of examining scour patterns and identifying lessons learnt. A further study covering both SED01 and SED02 topics was reported on in COWRIE (2010), drawing upon available new data at OWF sites in UK and European waters.

\section{Preliminary assessment of scour hazard}

Scour is a physical process related to the movement of the seabed sediment as a result of the flow of water away from a structure. The soil conditions are described by geotechnical parameters, therefore, scour is of a geotechnical nature as it relates to the reduction in ground level around a structure. Scour hazard assessment can be undertaken at a range of levels, which at its most simple could consist of an analysis of seabed features such as bedforms to identify seabed mobility in sands or identifying erosion in the case of clay soils (Whitehouse et al. 2010a). Where the seabed is mobile under the prevailing environmental conditions, it is inferred that the installation of a structure on the seabed may induce scouring (Whitehouse, 1998). Extending the analysis to include information on the known characteristics of the hydrodynamic conditions (waves and currents) combined with knowledge on the soil and assessing its mobility provides an understanding of the conditions under which the soil is mobile, and this can feed directly into the scour assessment methodology.

\section{Marine soils}

Scour in uniform sandy soils has been studied for decades and numerous methods have been proposed to estimate scouring in such non-cohesive soils. However, marine soils are often variable in their make up. Bed sediments of silty sand or sandy clay do not respond in the same way as sands without fines. Their resistance to erosion and rate of erosion is still an area of uncertainty and requires further examination so that a clearer understanding of scour for multi-modal sediment distributions can be achieved. Therefore, it will be informative to study further the role of unconsolidated fine sediments in scour evolution. There is uncertainty in the scour response of clays. The erosion rate of exposed clays due to hydraulic forces, abrasion through transport of granular sediments and weathering of the exposed surface on the seabed also requires further examination to determine the controlling mechanisms and the long-term progressive scour response. 
For scour assessments in general, it is very important to know the surficial soil characteristics, and data analysis starting from $1 \mathrm{~m}$ below the seabed or deeper in a foundation site investigation will not always be representative of the surface sediment properties required for a scour assessment. However, knowledge of the sediment properties below the surficial seabed layer will be important for predicting scour development with depth through the seabed.

The prediction of scour in cohesive or multi-modal soils (i.e. clay, silt, sand, gravel mixtures) is more complex. Typically the scour process is much slower; as a result the effect of scour is very much dependent on the period of time that the structure will remain at the site. Annandale (1995) proposed an approach to estimating the erosion potential of complex soils through the use of the stream power parameter, $P$, and its relationship to the ability of the soil to resist scour, defined through an Erodibility Index, $K$. The Erodibility Index provides a measure of the in situ strength of the material, whilst the stream power provides a measure of the rate of energy dissipation in the near-bed region due to hydrodynamic forces expressed by the following relationship:

$P=f(K)$

If $P$ exceeds the erosion threshold then scouring will occur. The approach was originally developed for looking at scouring of rock spillways, but the methodology applies equally to marine soils (Chapter 10, Annandale, 2006; Nairn and Anglin, 2002). Harris et al. (2010a) adapted the method developed by Annandale (2006) for marine soils. The Erodibility Index is defined as:

$$
K=M_{s} K_{b} K_{d} J_{S}
$$

Where $M_{S}$ is the mass strength number; $K_{b}$ is the block size number; $K_{d}$ is the discontinuity bond shear strength number and $J_{S}$ is the relative ground structure number (see Annandale, 2006, for further details). The approach allows for the physical properties of the soil to be considered and although the method does not directly take into account the chemical properties of the material, the mass strength number, $M_{S}$, represents the relative influence of chemical bonding properties of the soil through the unconfined compressive strength. 


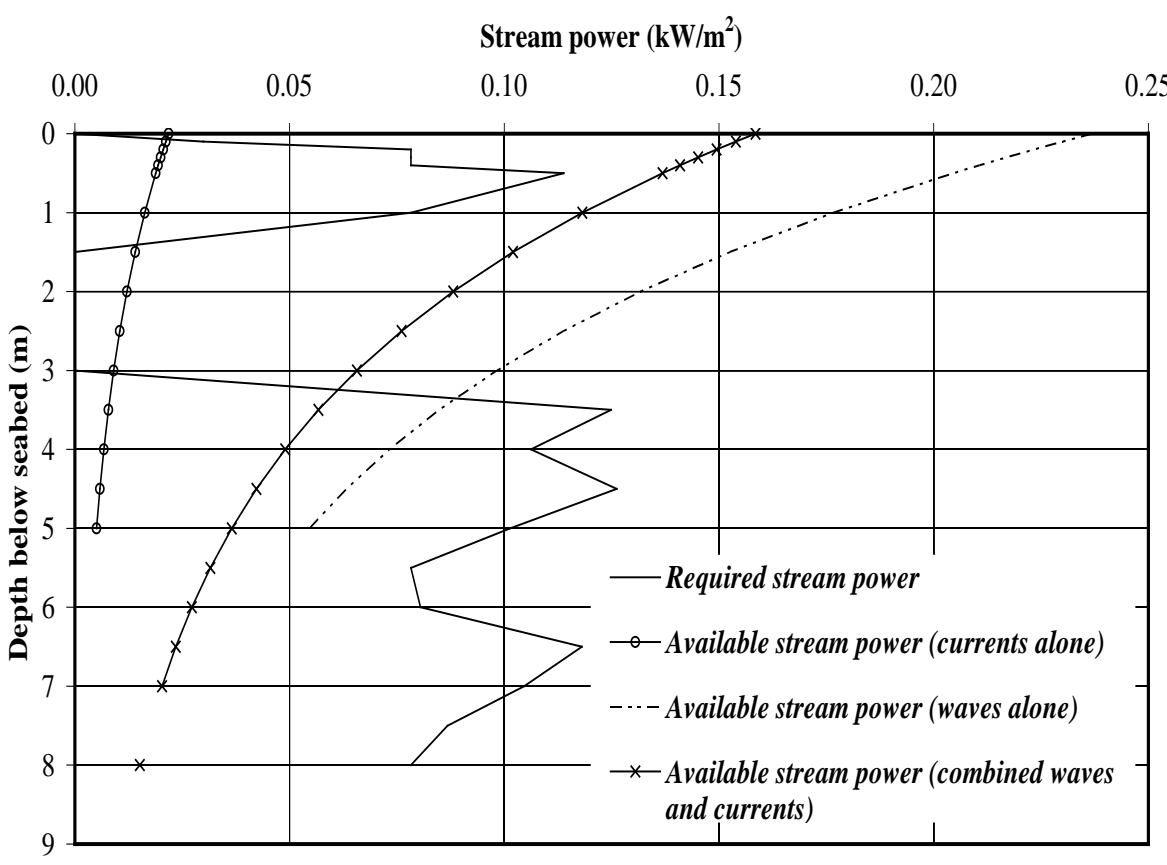

Figure 1 Plot showing the application of the Erodibility Index method to an offshore wind farm site with predominantly clay marine soils

Figure 1 shows an example application of the Erodibility Index method to a site in around $12.5 \mathrm{~m}$ of water with a thin sand, silt and clay surface veneer soil mixture with a clay layer underlying this and beneath this layer another mixed sand, silt and clay layer. The seabed veneer is generally to a depth of several decimetres, which is expected to scour due to the prevailing hydrodynamic conditions. The figure shows the variation with depth into the bed of the required stream power for erosion of an intact soil sample, with inputs derived directly from site investigation. The curves of available stream power, in increasing order, relate to currents alone, combined waves and currents and waves alone. The fact that the erosion potential due to waves alone is greatest in this example is a site specific result and not a general conclusion. The results shown are for 1:50 year return period conditions, therefore, the figure shows the potential scour extent, but whether this level of scour can be achieved will be related to the time-scale of the scour process, something that the current application of the Erodibility Index method cannot determine.

The time-scale of the scour process in complex soils can be achieved by monitoring the rate of erosion using appropriate equipment for in situ measurements of sediment erosion or by monitoring the scour development at a site with these types of soil following foundation installation. In uniform non-cohesive soils the time-scale of scour development can be estimated from existing empirical approaches (Whitehouse, 1998; Sumer and Fredsøe, 2002; Det Norske Veritas (DNV), 2007).

Appropriate in situ erosion equipment can be used to determine the erosion threshold and erosion rate of the soil. These devices can be applied to barrel core or box core samples obtained from site. Devices of this kind include ISIS and SedErode (Williamson and Ockenden, 1996; Mitchener et al., 1996), the Erosion Function Apparatus (EFA) (Briaud et al., 2001) and the Simulator of Erosion Rate Function (SERF) device (Jiang et al., 2004). Such devices can take a section of core or alternatively use a remoulded sample. The effect of the remoulding that takes place during foundation installation may be significant in determining soil strength, and hence resistance to erosion. 
Measurements can be made on samples from different levels in the bed to determine the variation of sediment erosion with depth. Analysis of the time-series data yields estimates of the threshold for erosion and the erosion rate as material is removed from the surface.

\section{Time-scale of scour development}

One of the outcomes from the SED02 study was that it was considered to be beneficial to start monitoring from the time of installation of any future sites, in order to examine the range of scales of contribution to scour development. This will capture the initial development and then if the monitoring is carried out for a number years it will provide the information required to extract the relative importance of waves and currents on scour development. Ideally the monitoring would be carried out in parallel with measurement of environmental data - directional wave information, current speed and direction, water depth and ambient bed level. A tide gauge installed on one of the foundations would provide a control dataset for water levels. Multibeam echo sounder data would provide the overall scour pattern around the foundation and a permanently installed downwards looking echo sounder would provide information on the variation of scouring in time, for correlation with the environmental data.

Recent studies by Harris et al. (2010b) suggest that the scour depth can vary significantly under combined current and wave conditions through time. Whitehouse (2006) had previously highlighted the need to develop time-series methods for scour development and, in particular, using the results from such methods to investigate the probability of exceedance of scour around the foundations of offshore structures.

The time variation with respect to the period between installation of the foundation structure and the monitoring survey or surveys is important as there will be a general increase in scour depth to some equilibrium condition over a time-frame that will vary with site conditions. Under steady flow conditions the scour depth development $S(t)$ (Whitehouse, 1998) is governed by $S_{e}$ the equilibrium scour depth, $T_{s}$ the characteristic time-scale of scour and $n$ an exponent generally taken to be equal to 1 :

$$
S(t)=S_{e}\left[1-\exp \left(-\frac{t}{T_{s}}\right)^{n}\right]
$$

Figure 2 shows field data from monitoring programmes at offshore wind farm sites in the UK of scour development at monopile foundations from the date of installation. The curve fit through the data represents a modification of the exponential growth curve referred to above. 


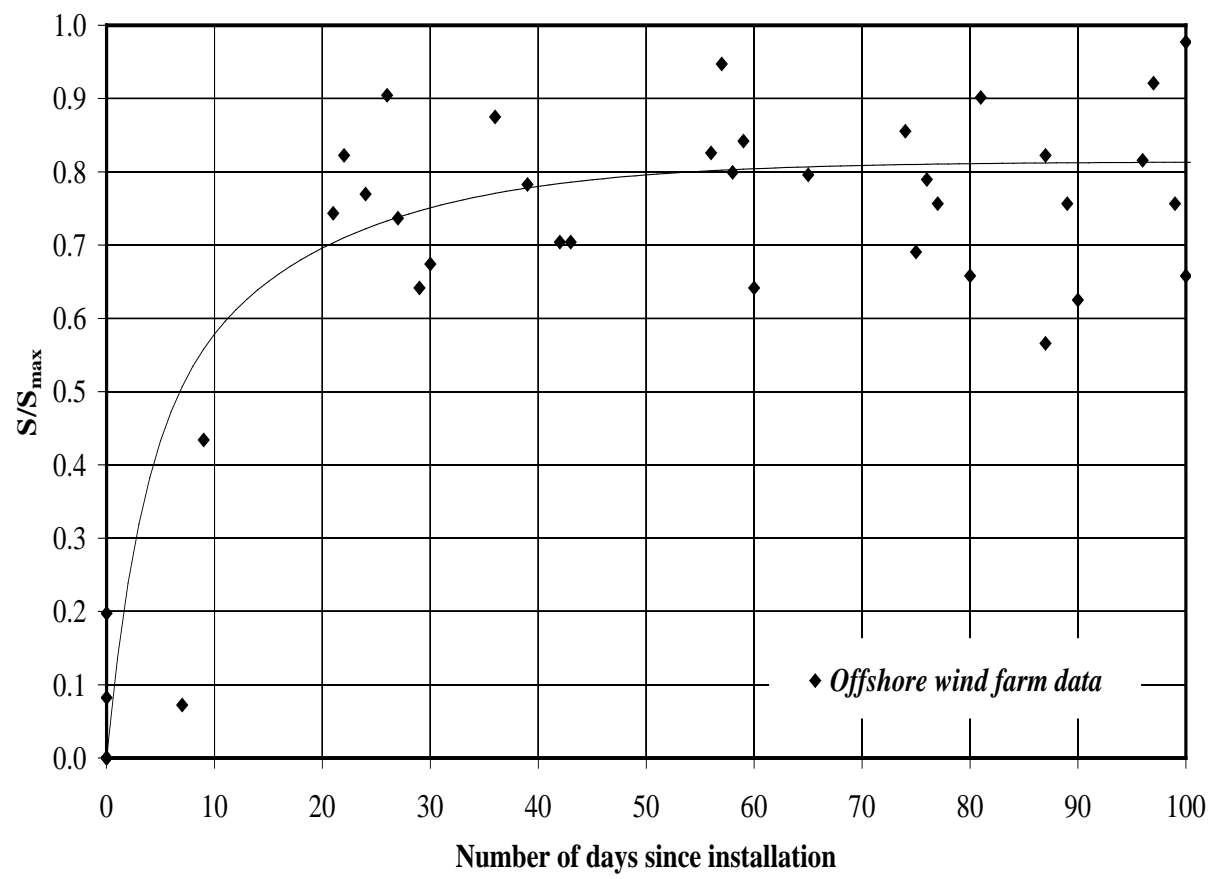

Figure 2 Plot showing the exponential growth of scour depth with time from turbine foundation installation

It should be noted in Figure 2 that three of the data points represent monopiles surveyed on day 0 with different levels of scour development. This is because the date of installation makes no differentiation of the time of survey relative to the installation time on day zero and thus time is recorded as zero.

Whitehouse et al. (2010b) present an analysis and interpretation of monitoring data for the seabed bathymetry local to offshore windfarm foundations has shown how the scour develops in time and highlighted variations between sites with different seabed sediment characteristics, i.e. sands and clays.

\section{Range of scour development}

The evidence database on scour, created primarily from monitoring data collected at UK Offshore Wind Farms, relates to monopile foundations in different sediment and hydrodynamic environments. The results from analysis of this monitoring data are presented in the standard parameters of scour depth $(S)$ nondimensionalised with foundation diameter $(D)$, and the water depth $(h)$ also non-dimensionalised by foundation diameter (Figure 3). It was noted previously in DECC (2008b) that the analysed data supports the view that scour is a progressive process where the seabed sediment is naturally mobile and there is an adequate thickness of that sediment for scouring to occur. Where the seabed is comprised of stiff clay, there is only a superficial layer of sediment overlying clay or the wave and current conditions are not generally strong enough to cause the seabed sediment to be naturally mobile, the scour will be slower or limited in depth. 


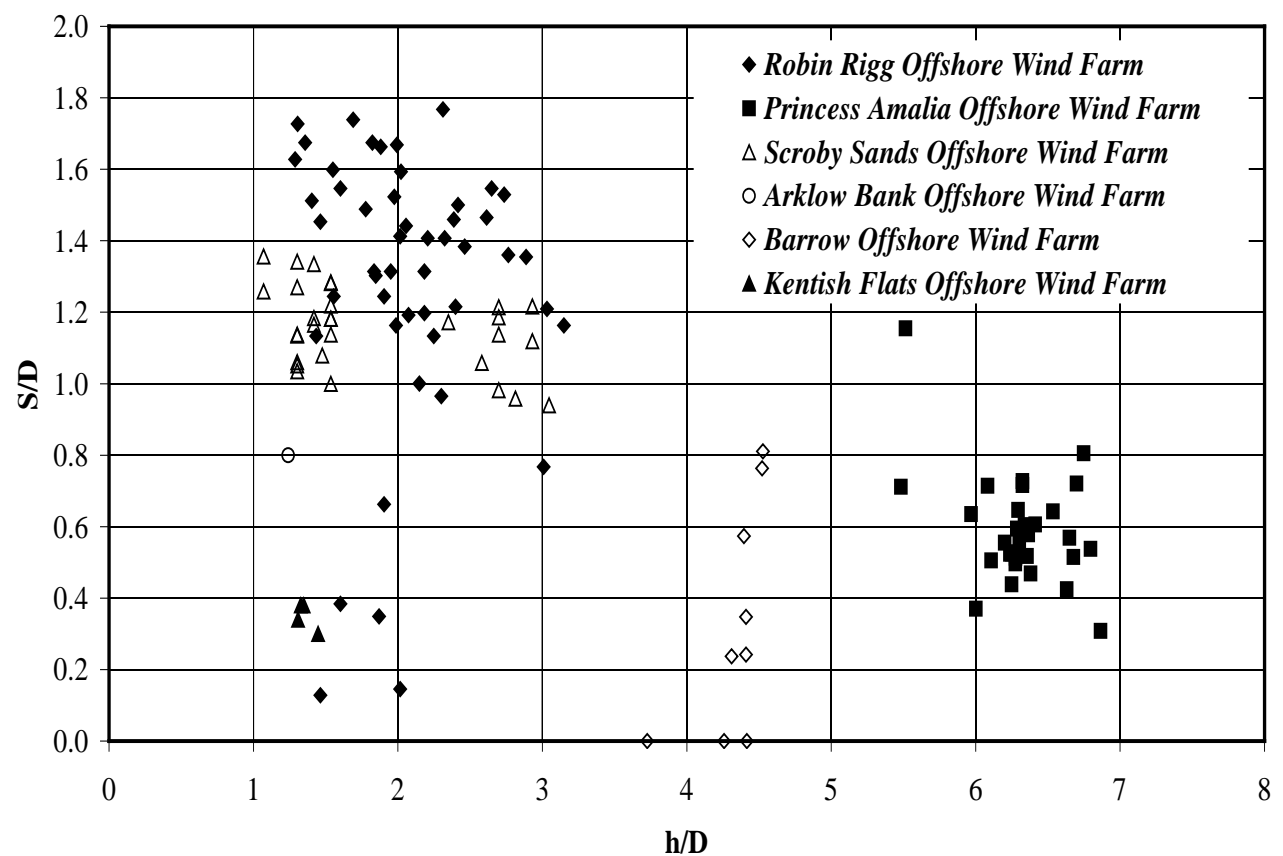

Figure 3 Non-dimensional plot of scour depth $(S)$ data for offshore wind farms with no foundation scour protection in place (Note: $D$ is monopile diameter and $h$ is water depth to mean sea level) (COWRIE, 2010)

Scour will occur from a continuously operating combination of tidal currents, either with negligible or a moderate amount of wave stirring, on a day-to-day basis. From laboratory experiments, the stronger currents occurring under spring tides can be expected to produce deeper scour than under neap tides. Under more extreme conditions, e.g. storm surges, larger currents may be generated and wave action can become significantly more energetic. Under these conditions the seabed sediment will be naturally more mobile. However, it is not clear whether the scour in an unlimited thickness of sandy sediment will be deeper or shallower during a storm with strong wave action. Research undertaken by Harris et al. (2010b) suggests that from model results waves suppress the scour development in sand, consistent with the equations used within the model. The range of tidal, seasonal (including storm events) and longer-term variations in currents, wave action and water levels can be expected to influence the way in which scour develops at a foundation, and this has an influence on foundation stability. The detailed time behaviour of scour in a varying wave and current environment remains to be measured.

\section{Field site characteristics}

This section provides an overview of the offshore wind farm sites for which data has been presented. A more detailed site description for the various wind farms can be found in DECC (2008b) and COWRIE (2010).

Kentish Flats Offshore Wind Farm is located in the outer Thames Estuary, approximately $9 \mathrm{~km}$ off the North Kent Coast and north of Herne Bay and Whitstable (Figure 4). The area lies to the south of the main Thames shipping channels and is bounded to the west by East Middle Sand and East Spaniard Banks and to the east by the Pan Sands Bank. The main export cables have a landfall at Hampton Pier, Herne Bay from where they run inland to a substation and connection with the National Grid. 




Figure 4 Location map for wind farm sites referred to in this paper

Construction of the wind farm was started in August 2004 and work was completed at the end of August 2005. The wind farm is composed of 30 turbines placed within a $10 \mathrm{~km}^{2}$ area of the seabed and the foundations consist of $4.3 \mathrm{~m}$ diameter monopile foundations. The monopiles were piled into the seabed with penetration depths of between 28 and $34 \mathrm{~m}$ below existing seabed levels. The seabed over the site has a general depth of between $3.0 \mathrm{~m} \mathrm{CD}$ and $4.5 \mathrm{~m}$ CD. Kentish Flats OWF became operational in September 2005.

The seabed at Kentish Flats is generally flat and subtly varied, comprising mainly coarse sand, but with varying amounts of shell gravel, whole dead shells, occasional pebbles and stacks of slipper limpets, very occasional cobbles and small exposures of the underlying clay. The sand is smooth or slightly rippled in places, but elsewhere are broadly spaced ridges and hollows. Geotechnical surveys at Kentish Flats show that the seabed consists of variable thickness of sand, underlain by soft to firm clays, on top of the London clay formation. The surficial sediment comprises muddy sands with shells and seaweed.

The most recent data for Kentish Flats has values of $S / D$ up to 0.4 . There is some evidence for fluctuations in scour with time at Kentish Flats, with two foundations apparently experiencing progressive scour depth increase over time. 
Barrow Offshore Wind Farm is situated about $8 \mathrm{~km} \mathrm{SW}$ of Walney Island in the Irish Sea (Figure 4). Thirty monopile foundations have been placed within the site, each of $4.75 \mathrm{~m}$ diameter, $D$. More information on the site is presented in DECC (2008b).

British Geological Survey (BGS, 1987) shows the seabed comprises muddy sands and sandy gravels across the entrance to Morecambe Bay, with exposures of Quaternary till. Titan Environmental Surveys (2002) undertook a geophysical survey of the wind farm site that provided further detail, showing the site as comprising mainly sand with concretions overlying tillite and clays, except in the shallower south east corner of the site where exposures of tillite and clays dominate and the surface sand becomes patchy. The depth of surface sediment reaches $10 \mathrm{~m}$ in the northwest but this depth includes bedded muddy sands as well as the surface layer of sand. The data for the clay dominated sites at Barrow show low (no) scour, as previously quoted (DECC, 2008b).

North Hoyle Offshore Wind Farm is situated approximately $7.5 \mathrm{~km}$ from the North Wales coast offshore of Prestatyn and Rhyl. The wind farm consists of thirty turbines in water depths varying between around $7 \mathrm{~m}$ to $11 \mathrm{~m}$ (LAT) which were installed by Seacore Ltd. over the period April to July 2003. The foundation units each comprise of $4.0 \mathrm{~m}$ diameter monopiles which were installed over the period April to July 2003. The turbines are arranged within a $10 \mathrm{~km}^{2}$ area of seabed licensed from The Crown Estate. The turbine array configuration is 5 columns and 6 rows, with respective separations of $800 \mathrm{~m}$ and $350 \mathrm{~m}$, approximately, between foundations.

The coastline is generally flat and predominantly sandy, although there are rocky islands at the mouth of the Dee Estuary (Hilbre, Little Hilbre and Little Eye), and there are also low-standing red sandstone cliffs along the western shoreline of Dee between Heswall and West Kirby.

Within the North Hoyle Wind Farm site the seabed sediments generally consist of sandy gravel or gravelly sand. Further offshore are larger patches of gravel mostly likely formed through the winnowing action of the waves combined with the tidal currents. Within these areas the gravels tend to exist as a thin layer overlying sand or boulder clay (BGS, 1992). The data from project specific sampling campaigns identify the site as being strongly heterogeneous, with variability over very short distances, as well as being composed of very poorly sorted sediments with varying contributions of sands and gravels mainly. Little (no) scour has been observed at this site recently and therefore data has not been plotted on Figure 3.

The Arklow Bank Wind Farm consists of $73.6 \mathrm{MW}$ wind turbines. Arklow Bank is a shallow water sandbank situated between $10 \mathrm{~km}$ and $12 \mathrm{~km}$ offshore from the eastern coast of Ireland and has some of the best wind resources in the Irish Sea. The Bank is subject to overall seabed movement, such as movement of the sandbank, channel migration and overall erosion and accretion. In addition, the installation of the $5 \mathrm{~m}$ diameter, $D$, monopile foundations for the wind turbines was predicted to cause local scour around the monopiles. Scour was caused by the strong currents that flow over the sandbank, often over $2 \mathrm{~m} / \mathrm{s}$, and design wave heights of almost $6 \mathrm{~m}$ on the offshore side. The water depth is as low as $5 \mathrm{~m}$ over the crest of the bank so depth-limited wave breaking occurs during severe storms.

The nearshore seabed of the east coast of Ireland is characterized by a series of shore-parallel linear sandbanks, trending in a north-south direction. Arklow Bank consists principally of sand, cobbles, shells and pebbles on the northern end which tend to fine sand at the southern end.

The Robin Rigg Offshore Wind Farm has been developed by E.ON UK. The wind farm site is located in the outer Solway Firth, on the sandbank known as Robin Rigg. The Solway Firth is situated on the north-west coast of the UK and separates England and Scotland (Figure 4). The seabed in the area of the wind farm consists of a series of banks orientated in a northeast to southwest direction moving from north to south 
across the estuary. The Robin Rigg and nearby Dumroof Banks are partially drying and seabed levels across this area of sandbanks vary from about $1.5 \mathrm{~m}$ above Chart Datum (CD) to deeper than $-16.5 \mathrm{~m} C D$ in some locations.

From the soil profiles taken during a 2004 site investigation at the Robin Rigg site the seabed comprises of sands inter-bedded with silts and clays overlying Glacial Till. The thickness of the deposits overlying the Glacial Till were reported to be in the range $17.0 \mathrm{~m}-21.0 \mathrm{~m}$, although at boreholes A1 and A9 thicknesses of $23.1 \mathrm{~m}$ and $28.8 \mathrm{~m}$ were reported, respectively (Osiris Projects, 2004).

The sand identified at bed level was typically reported as being fine or fine to medium. From the borehole records the sand is described as typically medium dense to dense; in contrast the cone penetration tests indicate that the sand is typically dense to very dense.

The silt and clay layers found within the sands were considered to be alluvial deposits formed from a reworking of the underlying Glacial Till. These deposits are generally described as being fine sandy silt or soft to firm clay.

Scroby Sands is a shore parallel bank and is approximately $11.4 \mathrm{~km}$ in length (north to south) and $1.8 \mathrm{~km}$ in width (east to west). The offshore facing side of the bank is steeper than the inshore side. The bank lies about $3 \mathrm{~km}$ offshore and dries at its southern end on low spring tides. It is partially covered by sand waves on its upper surface and flanks, and the surface of the bank comprises fine to medium sand with a median grain size $d_{50}$ of around $0.2 \mathrm{~mm}$ to $0.4 \mathrm{~mm}$.

Superimposed on the flanks and top of the sandbanks are sandwaves. In the shallower water depths wave action prevents sandwaves from developing fully, whilst in the deeper water the sandwaves can reach $3 \mathrm{~m}$ to $4 \mathrm{~m}$ in height. Along the flanks of the banks they are typically only $0.3 \mathrm{~m}$ to $0.5 \mathrm{~m}$ in height. Larger sandwaves, up to $8 \mathrm{~m}$ in height, are found on the seaward side of North Scroby (BGS, 1994), north of the wind farm.

The Princess Amalia (Q7) wind farm is the second offshore wind farm in the Dutch sector of the North Sea and the first to be located outside the 12 nautical mile limit. The turbines are located in water depths of between $19 \mathrm{~m}$ and $24 \mathrm{~m}$ and the wind farm is located approximately $23 \mathrm{~km}$ from IJmuiden, The Netherlands. The wind farm has an overall generating capacity of $120 \mathrm{MW}$, comprising 60 Vestas V80 $2 \mathrm{MW}$ wind turbines and has been operational since June 2008 .

The sediments at the Princess Amalia site have been described as being fine to medium sands $(0.125$ $0.500 \mathrm{~mm}$ ) with low organic carbon content due to the relatively strong current speeds that lead to a winnowing out of the fine grained sedimentary and organic particles. This is supported by the geophysical studies which describe the surficial sands as generally consisting of poorly graded fine to medium sand or medium sands. The silt/clay content is generally low within these sediments. However, from a Benthic study of the Q7 site (Jarvis et al., 2004) the median sediment characteristics have been quoted as $0.578 \mathrm{~mm}$ with a maximum grain size of $0.642 \mathrm{~mm}$ and a minimum of $0.470 \mathrm{~mm}$. This would suggest the surficial sediments to be coarse grade sand rather than fine to medium grade.

From the analysis of the data at the Princess Amalia OWF scouring at the majority of the turbines foundation appears to be limited. The scour data plotted in Figure 3 for the Princess Amalia OWF is in a cluster up to scour depths of $S / D=0.81$, with one value deeper at $S / D=1.15$.

To date Round 1 and Round 2 wind farms have been constructed in relatively shallow water. For the proposed Round 3 wind farm sites the water depths are generally deeper and, therefore, a wider range of foundation options are likely to be required. Of the monitoring data reported here, the data for the Princess 
Amalia OWF, in the Dutch Sector of the North Sea, represents site conditions that may be more indicative of those likely to be encountered at Round 3 sites.

Rudolph et al. (2008) undertook an analysis of the scour data for the Princess Amalia OWF and suggested that the lower scour depths (compared to the typically expected 1.5D) seen at this site were due to the balance between the scour and backfilling process. They concluded that during $10 \%$ of the time scour development took place and during about $90 \%$ of the time backfilling. On this basis it implies that both the scouring and backfilling processes are equally important in a scour assessment. The geophysical survey also indicates that underneath the eastern sandbank and the sandwave features to the west of the wind farm site, the sediments found at depths of between $3 \mathrm{~m}$ to $5 \mathrm{~m}$ are a soft to firm organic-rich clay. It is, therefore, possible that the clay deposits are also acting to limit scouring at some locations.

\section{Scour extents}

In sandy sediments the extents of a scour hole can be approximated based on the angle of repose, also termed angle of friction, of the sediment (e.g. Harris et al., 2010b). For steady flow conditions the upstream slope of the hole is the angle of repose, whilst the downstream slope is about half this angle $\pm 2^{\circ}$, approximately. The side slopes of the scour hole are about 5/6 of the angle of repose. Hoffmans and Verheij (1997) suggest that typical values for the angle of repose in sands are in the range of $26^{\circ}$ to $45^{\circ}$.

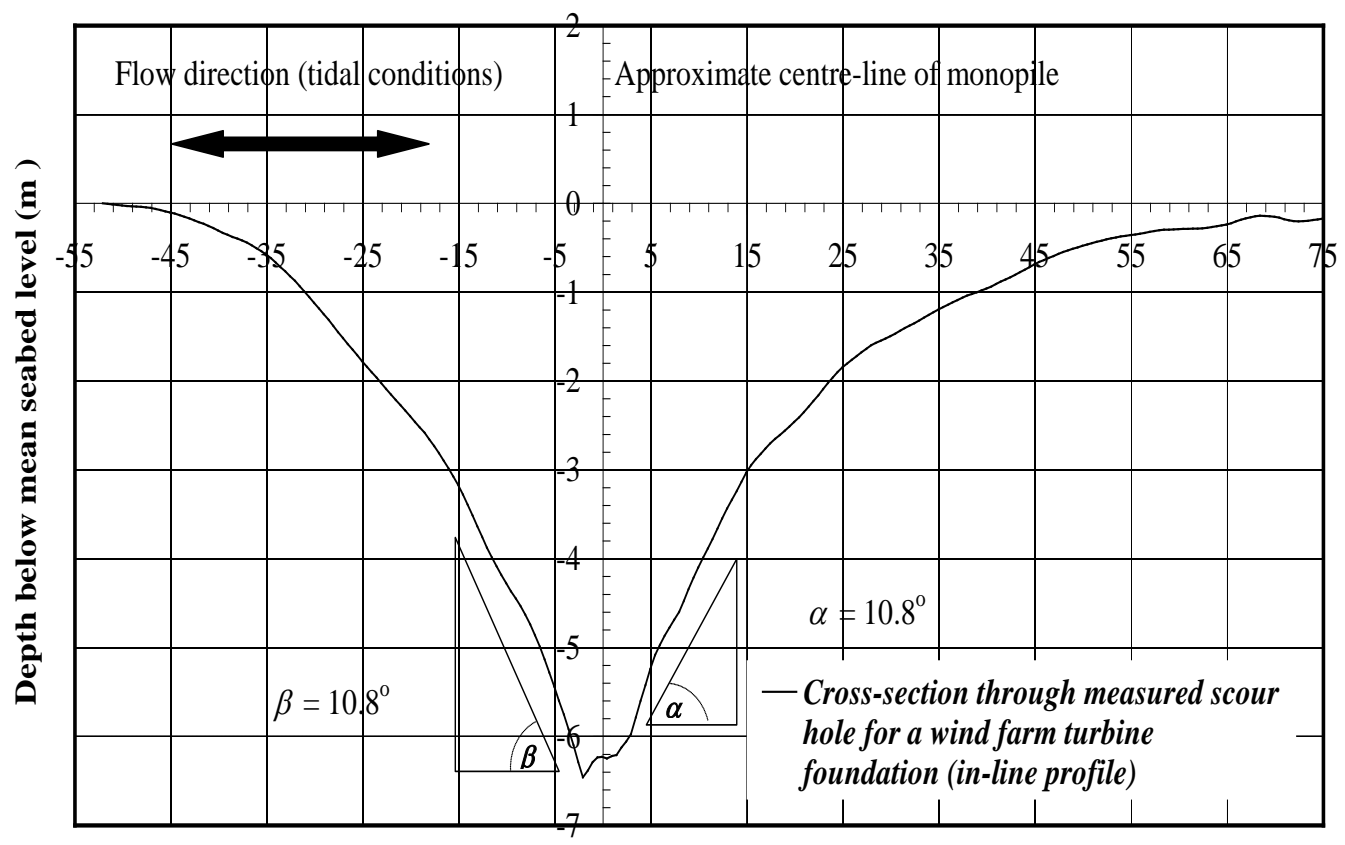

Distance (m)

Figure 5 Example scour hole profile in-line to principal flow axis from wind farm monitoring data

From monitoring of built offshore wind farms, the scour extents for foundation structures placed in morphologically dynamic tidal areas appear to be larger than would typically be estimated based on sediment angle of repose. Data suggests the angle of the steep inner portion of the scour hole is much lower than the angle of repose of the sediment and typically in the region of about $10^{\circ}$ (Figure 5). As the various sites where these elongated scour holes have been monitored have different seabed sediment 
characteristics such as grain size, it appears that the lower observed sediment angles are due more to the dynamic nature of the site rather than being related to a specific sediment type. However, further research is required to investigate this effect and the lags in the scour response to a change in flow direction with reversing tides, storm surge currents and waves. Also the form of the scour hole will change depending on the shape of the particular foundation structure, where this is not a monopile.

In more complex soils, predicting the scour extents is far more difficult. Existing methods given in guidance documents such as Det Norske Veritas (DNV) (2007) are applicable to scour prediction in an unlimited thickness of mobile sandy soil but do not include an allowance for the influence of complex soil properties on scour development. In complex soils the limiting effects of mixtures of sand, silt and clay and layered sediments should in principle act to limit the scour depth that develops compared with the mobile sand bed case and, therefore, limit the extents. In addition, in clay soils it is possible to maintain steeper side slopes and this will also influence scour hole development.

Physical modelling experiments conducted by one of the authors for a structure placed in a sand with an inerodible sediment layer located at half the depth of scour depth obtained from unconstrained sediment tests showed that the scour extents upstream of the foundation were reduced by about half. However, the lateral and downstream extents of the scour remained unchanged from those obtained in the unconstrained sediment tests. Therefore, the results suggest that the lateral and downstream extents are more controlled by the flow acceleration and eddy shedding from the structure. In reversing tidal flows it could be reasonably expected that both the "upstream" and "downstream" extents show a similar response, except for cases where there is a marked asymmetry in the tidal current.

\section{Scour protection}

Scour countermeasures have been applied at the Scroby Sands, Robin Rigg and Arklow Bank OWF sites.

The scour protection that has been placed appears to be effective in preventing bed lowering adjacent to the foundations. The interaction of the placed scour protection with the surrounding seabed levels has been examined from the available data. Where material has been placed in the scour hole formed around the foundation and the top level of the protection is above the level of the surrounding seabed level it is evident that the mound of protection material has produced a secondary scour response. The data that is available does not presently have the resolution to evaluate whether there has been any displacement of the protection material itself by wave and current action.

Studies undertaken for the Horns Rev I offshore wind farm, which is located in relatively shallow water (6.5 to $13 \mathrm{~m}$ water $(\mathrm{mtl}))$ around $20 \mathrm{~km}$ from the Danish west coast, have shown that the rock armour installed over the summer of 2002 had settled by as much of $1.5 \mathrm{~m}$ when re-surveyed in 2005 (Nielsen et al., 2010). The scour protection consisted of a two-layer cover (rock with a grading from around $350 \mathrm{~mm}$ to $550 \mathrm{~mm}$ ) and a $0.5 \mathrm{~m}$ thick granular filter layer (rock material with a grading from around $30 \mathrm{~mm}$ to $200 \mathrm{~mm}$ ) between the armour layer and the seabed. The site is exposed to strong tidal currents and large waves from the North Sea.

It is considered good practice for scour evaluation that during the design process of the foundation an appropriate analysis is made for local scour arising from the influence of waves and currents taking account of spring and neap conditions and the influence of storm events, as well as the relative magnitude of waves and currents, which will vary from location to location. In those locations where a strong reversing tidal flow exists it would be advisable to evaluate the influence of that current pattern on scour development. The potential for scour interaction between adjacent foundations needs to be assessed. Also, the influence of 
variation in bed level over the design life of the wind farm needs to be considered; this may arise from regional changes or local changes due to migration of seabed features such as banks, sandwaves or channels. The scour protection design needs to take appropriate account of these factors.

What has become evident from monitoring of built wind farms is that the cable connections into the turbines or substations can be prone to scouring. For example, at Scroby Sands OWF the cabling between turbines became exposed in the secondary scour pits formed around the scour protection. At the Arklow Bank site the cabling was exposed or abraded by the rock armour placed to protect the foundations (and possibly sediment movement) where it exited the J-tubes above the seabed. Further assessment is required of the occurrences of exposure of cables and what mitigation measures have or can be taken, e.g. re-trenching through jetting, rock dump or placement of concrete mattresses. If material has been placed over the cable it will be informative to see what data is available on the possible secondary scouring effects that may have been caused.

Whitehouse et al. (2010b) present a review of scour protection at built offshore wind farms where it has been installed at some sites for structural stability of the foundation or for cable protection. They demonstrate that the flow interaction with the protection can cause edge scour or secondary scour in the seabed around the protection, and in some cases this scour is deeper than the unprotected case.

\section{Discussion}

The scour data that have been made available from the built wind farm sites is an important resource and have been analysed and brought together to show how the scour depths from the different sites compare in terms of scour depth and ambient water depth (Figure 3). The evidence database relates to monopile foundations in different sediment and hydrodynamic environments. For those environments where sandy sediments dominate and the depth of this sandy sediment can be taken as being unlimited the deepest scour is of the order of $S I D=1.77$, with the majority of locations being less. The scatter in observed values for Robin Rigg, although some are not fully developed, are in line with expected values from predictive equations, i.e. 1.3D (DNV, 2007) to 1.75D (den Boon et al., 2004).

The methods given in DNV (2007) are applicable to scour prediction in unlimited thickness of mobile sandy soil and do not include an allowance for the influence of complex soil properties on scour development. The scour depth predictions using DNV would lie in the range of 0.1 pile diameters (lower end of wave dominated regime) to 1.3 pile diameters (current regime). Therefore, the approach as stated in DNV guidance would under-predict the scour occurring at sites such as Scroby Sands and Robin Rigg. However, it should be noted, that the original studies upon which this guidance is based suggest that the scour depth for live-bed current scour conditions is $S / D=1.3+\sigma_{S / D}$ where $\sigma_{S / D}$ is 0.7 (Sumer and Fredsøe, 2002) and that for design purposes the maximum scour depth is $S / D=1.3+2 \sigma_{S / D}$. This additional information has been omitted from the DNV document.

Earlier Breusers and Raudkivi (1991) suggested a value of $S / D=2.3$ when the flow velocity was four times the sediment threshold velocity. Below this condition they adopted a graphical approach to determining the multiplier based on experimental evidence. This would be in line with the approach given in Sumer and Fredsøe (2002).

The observed values cover the predicted range of scour that might be expected to occur up to around $2 D$. When these data are compared with those for the other built wind farms the results support a conclusion that scour calculations cannot ignore how the seabed soil structure varies with depth, i.e. limiting effects of complex soils. Therefore, geotechnical considerations are also important in the assessment of scour. 
The monitoring data from wind farm sites demonstrates a general exponential growth in scour with time (Figure 2). However, recent studies by Harris et al. (2010b) suggest that the scour depth can vary significantly under combined and variable strength current and wave conditions through time.

Figure 6 shows the percentage of scour below a given depth over the duration of the datasets at a shallow water, a moderate water depth site and a deeper water site using the methodology given in Harris et al. (2010b). The absolute value of maximum scour depth varies for each of the locations and of interest in the current paper is how the shape of the predicted distribution in scour depth compares for each location. For a mobile sediment in the deeper water site over $95 \%$ of the predicted scour depth variation through time is greater than $0.8 S_{\max }$. Therefore, it can be concluded that the variation in the scour depth at this site is low since scour depths less than this value also include the growth curve from the initiation of scouring. At the shallow water site around $45 \%$ of the predicted scour depths are greater than $0.8 S_{\max }$, with a similar shaped distribution, whilst at the moderate water depth site over $95 \%$ are less than $0.8 S_{\max }$, suggesting that there is more variability in scour depth at this location, and the distribution has a different shape to the other two locations.

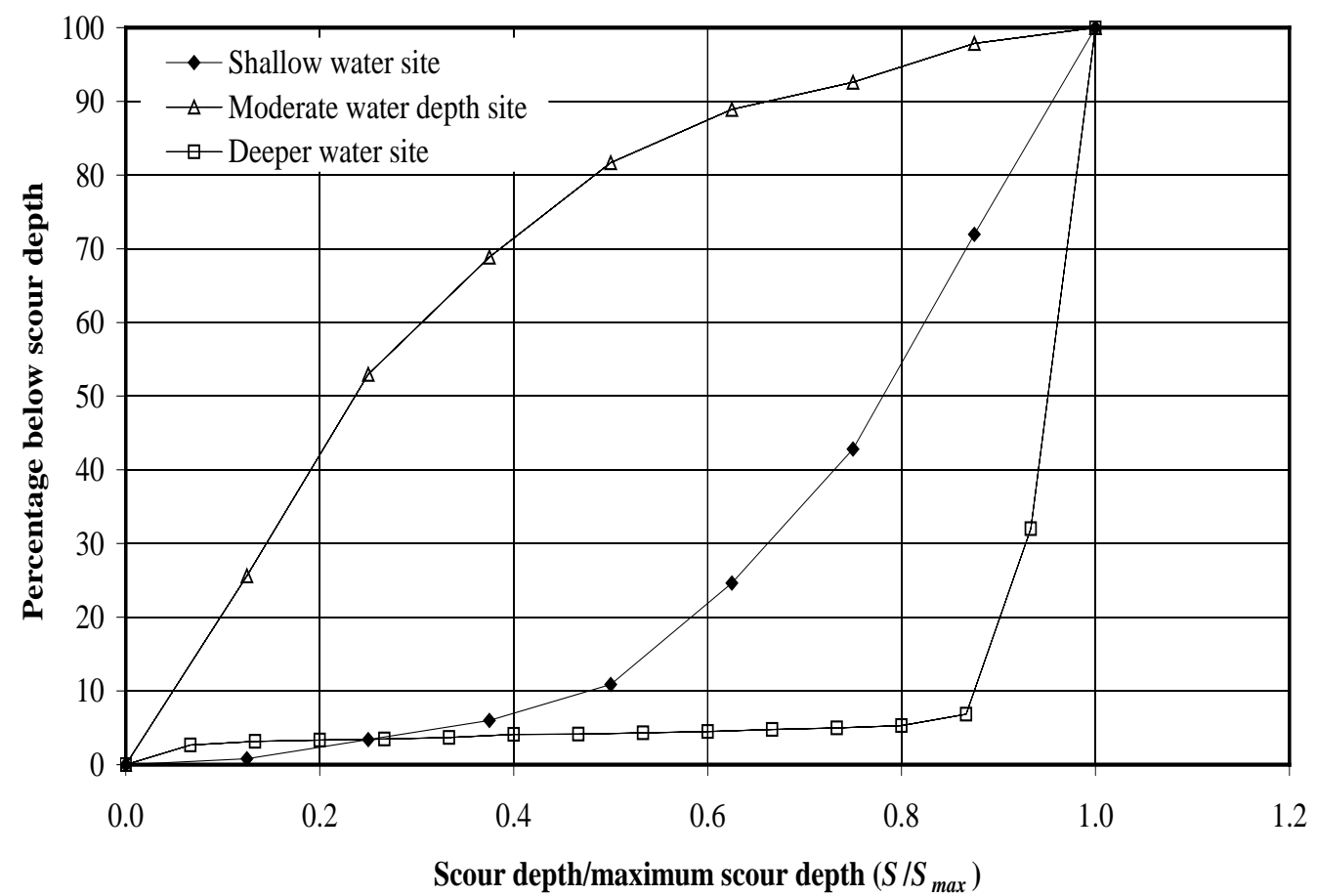

Figure 6 Percentage of predicted scour depths below a given depth for a range of water depths

It should be noted that the predicted maximum scour at shallow and moderate water depth sites show these locations to be depth limited with respect to scour development, which would mean that the equilibrium scour depth associated with the predictions referred to earlier in this section of the paper would be unlikely to occur.

Models such as those proposed by Harris et al. (2010b) can be used to provide insight into the behaviour of scour through time. However, such models based on empirical approaches are only as reliable as the predictive methods upon which they are based. For example, at the deeper water site it is possible that scour development is more limited than the model estimates, for example, due to mixed sediment effects. 
Therefore, the availability of monitoring data for scour at a range of sites with different depths but similar sediment properties would be invaluable in proving such approaches.

\section{Future challenges}

There are three distinct but related areas in which further research will lead to benefits in understanding and predicting scour response. The first relates to the scour potential and scour development with time in complex soils (gravel-sand-silt-clay mixtures); the second relates to complex foundation structures (gravity base, jacket and multi-leg foundations), and the third relates to the optimization of scour protection performance for monopile and complex foundation structures.

Dealing with the latter topic first, there is a lack of evidence as to the performance of installed scour protection around existing OWF sites (other than DECC, 2008b; Nielsen et al., 2010; Whitehouse et al., 2010b), therefore, if field measurements are available for foundations where protection has been used then it is recommended to:

- Carry out an ongoing analysis of the performance of the scour protection placed at operational sites and on new projects. As well as measurements of scour protection level and profile it would be useful to have sample visual information to show how the surface of the scour protection material varies with time. This could be obtained from a video camera lowered to the seafloor, or controlled by a diver or from a Remotely Operated Vehicle (ROV).

- Distil further guidance on the role of placement methodology in the evolution of the scour protection and the interaction of the protection with the surrounding seabed. In the longer term it will be useful to have data with which to evaluate the scour protection performance under the influence of regional changes in bed level, which can be especially important on sandbanks, or due to the movement of bedforms such as sandwaves and channels.

There is also an issue with time development of scour holes in a varying wave and current environment and this can have implications for installation of cables and placement of scour protection. A combined approach in laboratory and numerical modelling with field data collection is required.

With respect to complex foundations, any uncertainties are primarily related to design and impact on operational conditions. For foundation structures other than monopiles it is necessary to use a combination of approaches to estimate likely scour around the foundation. The lack of general suitability of these approaches leads to an uncertainty in the design process. Further, the representation of more complex foundation types in the typical shallow water coastal modelling systems that are used in the environment assessments is a large uncertainty. This uncertainty can be reduced through a programme of detailed laboratory experiments combined with numerical modelling.

There is also uncertainty about scouring around foundations in complex multi-modal soils. Whilst methods such as those presented in this paper are applied, there is currently no general guidance as to how to assess scour potential in such situations. Therefore, there is a requirement for a review of available methods with field observations, leading to recommendations as to the most appropriate approaches to adopt, and a requirement for new guidance documentation to cover complex soils and foundation structures.

Ultimately, the economic costs of the type of offshore developments described within this paper can be reduced by greater certainty in the prediction of seabed response, in combination with the design of more efficient foundation solutions. However, only designs that have been tried and tested and shown to be reliable will be adopted by developers as there is also a requirement for the technology to be proven before its application for use in large-scale developments. 


\section{Nomenclature}

$$
\begin{array}{ll}
D & =\text { external diameter of pile }(\mathrm{m}) \\
h & =\text { total water depth }(\mathrm{m}) \\
J_{S} & =\text { the relative ground structure number } \\
K_{b} & =\text { the block size number } \\
K_{d} & =\text { the discontinuity bond shear strength number } \\
M_{S} & =\text { the mass strength number } \\
n & =\text { exponent } \\
S & =\text { scour depth (m) } \\
S(t) & =\text { scour depth with time }(\mathrm{m}) \\
S_{e} & =\text { equilibrium scour depth }(\mathrm{m}) \\
t & =\text { time (s) } \\
T_{S} & =\text { characteristic time-scale of scour }(\mathrm{s})
\end{array}
$$

\section{Acknowledgments}

The research presented in this paper was made possible through the support received from offshore wind farm developers whose data and information has been kindly shared with the authors. The authors would also like to acknowledge the various funding sources which made the research possible including the panGovernment Research Advisory Group (RAG), COWRIE and the company research programme of HR Wallingford.

\section{References}

Annandale, G.W. (1995). Erodibility. Journal of Hydraulic Research, 33 (4), 471-494.

Annandale, G.W. (2006). Scour Technology. Mechanics and Engineering Practice. McGraw-Hill.

BGS (1987). Seabed Sediments around the United Kingdom (South Sheet): 1:1,000,000. British Geological Survey.

BGS (1992). Marine Aggregate Survey Phase 4: Irish Sea. BGS Marine Report WB/92/10.

BGS (1994). Memoir Report - Geology of the Country around Great Yarmouth. HMSO, London.

Breusers, H.N.C. and Raudkivi, A.J. (1991). Scouring. IAHR Hydraulic Structures Design Manual, 2, A. A. Balkema, Rotterdam, vii + 143 pp.

Briaud, J.-L., Ting, F.C.K., Chen, H.C., Cao, Y., Han, S.W. and Kwak, K.W. (2001). Erosion function apparatus for scour rate predictions. Journal of Geotechnical and Geoenvironmental Engineering, 127, pp. 105-113. 
COWRIE (2010). A Further Review of Sediment Monitoring Data. Final Report prepared by ABPmer Ltd, HR Wallingford Ltd and CEFAS for the Research Advisory Group, Project Ref. ScourSed-09, March, 115 p.

DECC (2008a). Review of Round 1 Sediment Process Monitoring Data - Lessons Learnt. Final Report prepared by ABP Marine Environmental Research Ltd, HR Wallingford Ltd and Centre for Environment, Fisheries and Aquaculture Science for the Research Advisory Group, Department of Energy and Climate Change (DECC) and Department for Environment, Food and Rural Affairs (Defra).

DECC (2008b). Dynamics of scour pits and scour protection - Synthesis report and recommendations (Milestones 2 and 3). Final Report prepared by HR Wallingford Ltd, ABP Marine Environmental Research Ltd and Centre for Environment, Fisheries and Aquaculture Science for the Research Advisory Group, Department of Energy and Climate Change (DECC) and Department for Environment, Food and Rural Affairs (Defra).

Den Boon, H., Sutherland, J., Whitehouse, R., Soulsby, R., Stam, C-J., Verhoeven, K., Høgedal, M. and Hald, T. (2004). Scour Behaviour and scour protection for monopile foundations of offshore wind turbines. Proceedings of the European Wind Energy Conference [CD-ROM].

Det Norske Veritas. (2007). Design of Offshore Wind Turbine Structures, Offshore Standard DNV-OS-J101, 142pp.

Harris, J.M., Whitehouse, R.J.S. and Sutherland, J. (2010a). Scour assessment in complex marine soils - an evaluation through case examples. In: Proc. of the fifth International Conf. on Scour and Erosion, (eds.) Burns, S.E., Bhatia, S.K., Avila, C.M.C. and Hunt, B.E., Nov. 7 - 10, San Francisco, California, USA, Geotechnical Special Publication no. 210, ASCE, pp. 450 - 459.

Harris, J.M., Whitehouse, R.J.S. and Benson, T. (2010b). The time evolution of scour around offshore structures. Proceedings of the Institution of Civil Engineers, Maritime Engineering, 163, March, Issue MA1, pp. $3-17$.

Hoffmans, G.J.C.M. and Verheij, H.J. (1997). Scour Manual. Balkema, Netherlands.

Jarvis, S., Allen, J., Proctor, N., Crossfield, A., Dawes, O., Leighton. A., McNeill, L. and Musk, W. (2004). North Sea Wind Farms: Q7 Lot 1 Benthic Fauna. Final Report. Report ZBB607.1-F-2004, Institute of Estuarine \& Coastal Studies, University of Hull, $89 \mathrm{pp}$.

Jiang, J., Ganju, N.K and Mehta, A.J. (2004). Estimation of contraction scour in riverbed using SERF. Journal of Waterway, Port, Coastal, and Ocean Engineering, 130, pp. 215-218.

Mitchener, H.J., Whitehouse, R.J.S., Soulsby, R.L. and Lawford, V.A. (1996). Development of SedErode Instrument for In-Situ mud erosion measurements. Report TR17, HR Wallingford, 17pp (+tables and figures).

Nairn, R.B. and Anglin, C.D. (2002). Confederation Bridge - New scour design methodology for complex materials. In: Proc. of the first International Conf. on Scour and Erosion, (eds.) Chen, H-C. and Briaud, J-L., Nov. 17 - 20, Texas A\&M University, College Station, Texas, USA, Vol. 2, pp. 978-992.

Nielsen, A.W., Sumer, B.M., Fredsøe, J. and Christensen, E.D. (2010). Scour protection around offshore wind turbines monopiles. In: Proc. of the fifth International Conf. on Scour and Erosion, (eds.) Burns, S.E., Bhatia, S.K., Avila, C.M.C. and Hunt, B.E., Nov. 7 - 10, San Francisco, California, USA, Geotechnical Special Publication no. 210, ASCE, pp. $440-449$.

Osiris Projects (2004). Robin Rigg Proposed Offshore Windfarm Development, Geophysical Surveys, Volumes 1 (Survey Report) and 2 (Operations Report), September 2004. 
Rudolph, D., Raaijmakers, T. and Stam, C-J. (2008). Time-dependent scour development under combined current and wave conditions - hindcast of field measurements. Proceedings Fourth International Conference on Scour and Erosion, Tokyo, Japan, Paper B-15, 340-347.

Sumer, B.M. and Fredsøe, J. (2002). The Mechanics of Scour in the Marine Environment. Advanced Series on Ocean Engng., Vol. 17, World Scientific, Singapore. xiii + 536 pp.

Titan Environmental Surveys Ltd. (2002). Barrow Offshore Generation Geophysical Survey. Final Report.

Whitehouse, R.J.S (1998). Scour at marine structures: A manual for practical applications. Thomas Telford, London, $198 \mathrm{p}$.

Whitehouse, R. (2006). Scour at coastal structures (Invited lecture). Proceedings Third International Conference on Scour and Erosion, November 1-3, pp. 52-59, (c) CURNET, Gouda, The Netherlands [CD$\mathrm{ROM}]$.

Whitehouse, R.J.S., Harris, J.M., Mundon, T.R. and Sutherland, J. (2010a). Scour at offshore structures. In: Proc. of the fifth International Conf. on Scour and Erosion, (eds.) Burns, S.E., Bhatia, S.K., Avila, C.M.C. and Hunt, B.E., Nov. 7 - 10, San Francisco, California, USA, Geotechnical Special Publication no. 210, ASCE, pp. $11-20$.

Whitehouse, R.J.S., Harris, J.M., Sutherland, J. and Rees, J. (2010b). The nature of scour development and scour protection at offshore windfarm foundations. Mar. Pollut. Bull., doi:10.1016/j.marpolbul.2010.09.007.

Williamson, H.J. and Ockenden, M.C. (1996). ISIS - an instrument for measuring erosion stress in-situ. Estuarine, Coastal and Shelf Science, Vol. 42, 1-1. 